\title{
PERBANDINGAN KUAT TEKAN PAVING BLOCK RAMAH LINGKUNGAN BERBASIS LIMBAH BOTOL PLASTIK KEMASAN AIR MINERAL DENGAN LIMBAH CANGKANG KERANG DAN LIMBAH BOTOL KACA SEBAGAI BAHAN SUBSTITUSI TERHADAP SEMEN
}

\author{
Indah Handayasari $^{(1)}$, Gita Puspa Artiani ${ }^{(2)}$ \\ 1,2 Program Studi Teknik Sipil, Sekolah Tinggi Teknik PLN, JI. Lingkar Luar Barat, Duri Kosambi, \\ Cengkareng, Jakarta Barat 11750, Telp.(021) 5440342, Fax. (021) 5440343, email: \\ indah.handayasari@sttpln.ac.id
}

\begin{abstract}
Among various kinds of alternative building material products used as cover or hardening of soil surface, Paving blocks are products that are in great demand by consumers. As a covering material and ground surface hardening, Paving blocks are widely used for various purposes, ranging from hardening and beautifying road sidewalks, road hardening, hardening of parking areas, and can even be used in special areas such as container ports and airports. This is because Paving blocks have advantages from other products in terms of shape, size, color and style. In addition, Paving blocks can be combined with other cover materials. Considering the use of Paving blocks that are quite extensive, it is necessary to have alternative substitute materials that can reduce the use of natural materials due to increased physical infrastructure development but are environmentally friendly. One of the eco-friendly Paving block alternatives is by utilizing plastic bottle waste packaging as mineral water as sand substitution material as well as green seashell waste and glass bottle waste as cement substitution material in making Paving blocks. In this study samples were made by comparing the composition of plastic bottle waste packaging of mineral water, seashell waste and glass bottle waste with $0 \%, 5 \%, 10 \%, 15 \%$ and $20 \%$ substitution treatment of the dry weight of Paving blocks. The test results showed that the optimum mixture variation was found in a mixture with a variation of $10 \%$ of plastic bottle waste packaging of mineral water $+10 \%$ of seashell waste with a compressive strength of $12.8 \mathrm{MPa}$ and a percentage of water absorption at 28 days of $2.63 \%$. Where the results of the variations in Paving blocks are categorized into quality $C$ which can be used for pedestrians.
\end{abstract}

Keywords : Paving Blocks, Waste, Compressive Strength.

\section{PENDAHULUAN}

Paving block merupakan bahan penutup dan pengerasan permukaan tanah yang sangat luas penggunaannya untuk berbagai keperluan, mulai dari keperluan yang sederhana sampai penggunaan yang memerlukan spesifikasi khusus. Paving block dapat digunakan untuk pengerasan dan memperindah trotoar jalan di kota-kota, pengerasan jalan kawasan pemukiman, memperindah taman, pengerasan area parkir, area perkantoran bahkan dapat digunakan pada area khusus seperti pada pelabuhan peti kemas, bandar udara, terminal bis dan stasiun kereta. Mengingat banyaknya penggunaan Paving block sebagai salah satu bahan konstruksi yang berfungsi sebagai bahan penutup/perkerasan permukaan tanah maka pada penelitian ini memanfaatkan bahan limbah botol plastik kemasan air mineral sebagai bahan pengganti sebagian agregat halus serta limbah cangkang kerang hijau dan limbah botol kaca sebagai bahan pengganti sebagian semen dalam pembuatan Paving block yang diharapkan tidak hanya dapat memberikan alternatif Paving block yang ramah lingkungan tetapi juga dapat memenuhi ketentuan 
yang disyaratkan. Selain itu pula dengan substitusi yang dilakukan terhadap agregat halus maupun semen tersebut diharapkan dapat mempunyai ikatan yang baik agar Paving block tahan lama serta mengurangi penyerapan air sehingga keawetan Paving block dapat meningkat.

Pemilihan bahan limbah botol plastik kemasan air mineral sebagai bahan pengganti sebagian agregat halus didasarkan pada hasil penelitian Arif Frasman Sibuea ${ }^{(1)}$ yang menunjukkan bahwa penambahan serat plastik sebanyak $(0,25-1,0) \%$ pada adukan Paving block dapat meningkatkan kuat tekan dengan peningkatan kuat tekan maksimum pada penambahan serat plastik $0,5 \%$ yaitu sebesar $42,23 \%$. Berdasarkan penelitian Dian Rifany K, dkk. ${ }^{(2)}$ juga menunjukkan pemanfaatan teknologi tepat guna hasil pengelolaan sampah, seperti limbah plastik, styrofoam, sekam padi, kertas dan serbuk kayu memberikan hasil bahwa limbah tersebut dapat dijadikan sebagai alternatif bahan bangunan. Pada penelitian R. Agus Murdiyoto ${ }^{(3)}$ yang memanfaatkan limbah botol plastik jenis PET (Poly Ethylene Terephthalate) untuk agregat kasar pembuatan Paving block memberikan hasil yaitu dengan penambahan agregat kasar sebesar 15\% nilai rata-rata kuat tekannya menjadi maksimum yaitu sebesar $132,73 \mathrm{~kg} / \mathrm{cm}^{2}$ dan diklasifikasikan sebagai Paving block kelas mutu C yang dapat digunakan untuk pejalan kaki. Kenaikan kuat tekan Paving block disebabkan bahan tambah agregat kasar bersifat polimer semi kristalin.

Pengunaan limbah cangkang kerang hijau dan limbah botol kaca sebagai bahan pengganti sebagian semen dalam pembuatan Paving block didasarkan pada hasil percobaan Erwin Wijaya Kusuma ${ }^{(4)}$ yang menunjukan bahwa hasil terbaik dari pengujian penyerapan air dan uji kuat tekan Paving block dapat dicapai pada rasio perbandingan pasir 80\%, kulit kerang 20\% dengan umur Paving block 28 hari. Pada komposisi ini Paving block memiliki kadar air 2,94\% dan uji kut tekan 46,79 Mpa yang memenuhi SNI 03-0691-1996. Selain itu juga dari hasil pengujian Rida Madya T. F. R.dkk. ${ }^{(5)}$ dengan campuran Paving block yang memanfaatkan bahan tambah serbuk kaca $10 \%$ hasil pengolahan limbah botol kaca terhadap berat semen menghasilkan kekuatan optimum pada umur 28 hari sebesar $13,625 \mathrm{Mpa}$ dan mengalami peningkatan $25,86 \%$ dari Paving block tanpa menggunakan campuran serbuk kaca.

Berdasarkan beberapa hasil penelitian tersebut maka pada penelitian ini akan membadingkan kuat tekan Paving block berbasis limbah botol plastik kemasan air mineral dengan limbah cangkang kerang dan limbah botol kaca sebagai bahan substitusi terhadap semen. Penelitian yang dilakukan akan meninjau pengaruh komposisi limbah botol plastik kemasan air mineral serta limbah cangkang kerang hijau dan limbah botol kaca terhadap karakteristik kuat tekan Paving block dan persentase penyerapan air yang terjadi.

\section{METODE PENELITIAN}

Paving block sendiri menurut SNI 03-0691-1996 ${ }^{(6)}$ didefinisikan sebagai suatu komposisi bahan bangunan yang dibuat dari campuran semen portland atau bahan perekat hidrolis sejenisnya, air dan agregat dengan atau tanpa bahan tambahan lainnya yang tidak mengurangi mutu Paving block tersebut. 
Metode yang digunakan dalam pembuatan Paving block dengan pemanfaatan limbah botol plastik kemasan air mineral serta limbah cangkang kerang hijau dan limbah botol kaca sebagai bahan substitusi adalah metode eksperimental dengan pengujian dilaboratorium yang didahului studi literatur yang mendukung penelitian agar diperoleh hasil yang optimal dan sesuai dengan tujuan pekerjaan. Tahapan pelaksanaan penelitian meliputi :

1. Persiapan Alat dan Pengujian Material

Persiapan peralatan yang akan digunakan dan pengujian material utama pembuatan yang akan dilaksanakan pada Laboratorium Struktur Beton Program Studi Teknik Sipil STT-PLN.

2. Pembuatan Sampel Penelitian :

Pembuatan sampel untuk penelitian ini dengan variasi campuran masing-masing limbah botol plastik kemasan air mineral maupun limbah cangkang kerang hijau dan limbah botol kaca yang digunakan adalah $0 \%, 5 \%, 10 \%, 15 \%$ dan $20 \%$ dari berat kering Paving block. Dimana limbah botol plastik kemasan air mineral substusi terhadap agregat halus serta limbah cangkang kerang hijau dan limbah botol kaca substusiti terhadap semen. Benda uji disiapkan masing-masing 3 buah untuk pengujian kuat tekan dengan pengujian sampel pada umur 7 hari, 14 hari dan 28 hari. Sedangkan benda uji untuk pengujian penyerapan air disiapkan masingmasing 3 buah dengan pengujian sampel pada umur 14 hari dan 28 hari.

3. Tahap Analisa

Setelah didapatkan data hasil pengujian kemudian dilakukan analisa dan pembahasan serta membandingkan sifat, kuat tekan dan penyerapan air dari setiap data tersebut.

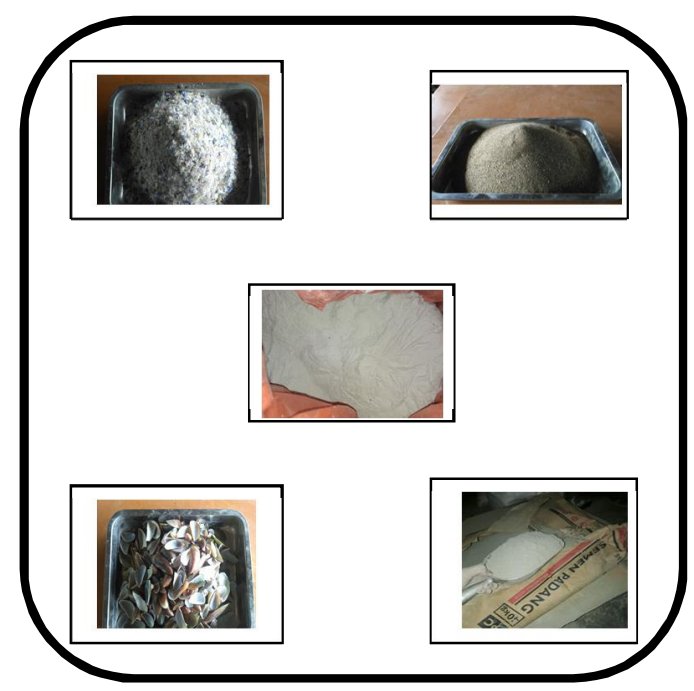

Gambar 1. Material Campuran Paving block

\section{HASIL DAN PEMBAHASAN}

Pengujian kuat tekan ditinjau pada benda uji 7 hari, 14 hari dan 28 hari. Adapun hasil dari pengujian kuat tekan Paving block dengan substitusi limbah botol plastik dan cangkang kulit kerang dapat dilihat pada Tabel 1 dan Tabel 2. 
Berdasarkan grafik nilai kuat tekan dan tabel persentase penyerapan air pada Paving block dengan substitusi limbah botol plastik dan cangkang kulit kerang diatas menunjukkan hasil bahwa penggunaan limbah botol plastik dan limbah cangkang kerang tersebut mampu meningkatkan niai kuat tekan Paving block. Nilai kuat tekan optimum untuk umur 28 hari didapatkan pada variasi Paving block substitusi 10\% limbah botol plastik $+10 \%$ limbah cangkang kerang dengan nilai kuat tekan sebesar $12,8 \mathrm{MPa}$ serta nilai persentase penyerapan didapatkan sebesar 2,63\%. Berdasarkan ketentuan SNI 03-0691-199 dengan hasil variasi Paving block tersebut dikategorikan ke dalam mutu $\mathrm{C}$ yang dapat digunakan untuk pejalan kaki.

Tabel 1. Hasil Uji Kuat Tekan Paving block

\begin{tabular}{|c|c|c|c|c|}
\hline Variasi & Hari & $\begin{array}{c}\text { Luas } \\
\text { Permukaan } \\
\left(\mathbf{c m}^{2}\right) \\
\end{array}$ & $\begin{array}{c}\text { Kuat Tekan } \\
\text { Rata-rata } \\
\left(\mathrm{Kg} / \mathrm{cm}^{2}\right)\end{array}$ & $\begin{array}{c}\text { Kuat Tekan } \\
\text { Rata-rata } \\
\text { (MPa) }\end{array}$ \\
\hline \multirow{3}{*}{$\begin{array}{l}\text { 0\% Limbah Botol Plastik }+ \\
0 \% \text { Limbah Cangkang Kerang }\end{array}$} & 7 & 200 & 62,25 & 6,2 \\
\hline & 14 & 200 & 73,3 & 7,3 \\
\hline & 28 & 200 & 78,2 & 7,8 \\
\hline \multirow{3}{*}{$\begin{array}{l}\text { 5\% Limbah Botol Plastik }+ \\
\text { 5\% Limbah Cangkang Kerang }\end{array}$} & 7 & 200 & 65,8 & 6,6 \\
\hline & 14 & 200 & 87,5 & 8,8 \\
\hline & 28 & 200 & 96,7 & 9,8 \\
\hline \multirow{3}{*}{$\begin{array}{c}\text { 10\% Limbah Botol Plastik }+10 \% \text { Limbah } \\
\text { Cangkang Kerang }\end{array}$} & 7 & 200 & 102,5 & 10,3 \\
\hline & 14 & 200 & 106,7 & 10,7 \\
\hline & 28 & 200 & 127,5 & 12,8 \\
\hline \multirow{3}{*}{$\begin{array}{c}\text { 15\% Limbah Botol Plastik }+15 \% \text { Limbah } \\
\text { Cangkang Kerang }\end{array}$} & 7 & 200 & 50,8 & 5,1 \\
\hline & 14 & 200 & 60,8 & 6,1 \\
\hline & 28 & 200 & 73,3 & 7,3 \\
\hline \multirow{3}{*}{$\begin{array}{c}20 \% \text { Limbah Botol Plastik }+20 \% \text { Limbah } \\
\text { Cangkang Kerang }\end{array}$} & 7 & 200 & 16,7 & 1,7 \\
\hline & 14 & 200 & 25,8 & 2,6 \\
\hline & 28 & 200 & 33,3 & 3,3 \\
\hline
\end{tabular}

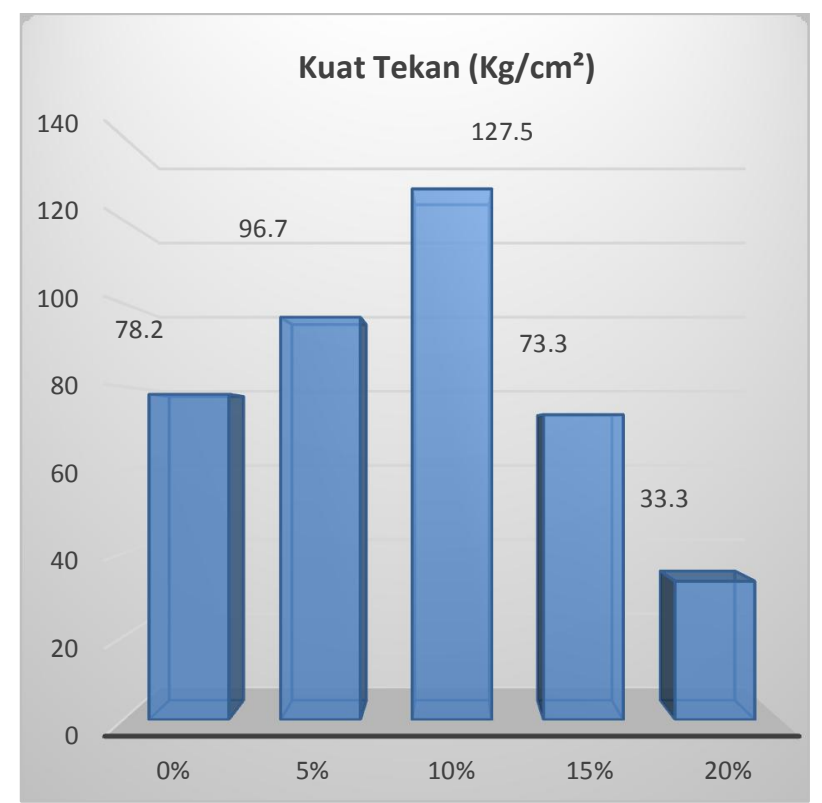

Gambar 2. Hasil Pengujian Kuat Tekan Paving block Umur 28 Hari 
Tabel 2. Hasil Uji Penyerapan Air Paving block

\begin{tabular}{ccc}
\hline Variasi & Hari & Rata-rata Penyerapan (\%) \\
\hline 0\% Limbah Botol Plastik + & 14 & 5,22 \\
0\% Limbah Cangkang Kerang & 28 & 3,82 \\
5\% Limbah Botol Plastik + & 14 & 5,94 \\
5\% Limbah Cangkang Kerang & 28 & 3,71 \\
10\% Limbah Botol Plastik + & 14 & 3,89 \\
10\% Limbah Cangkang Kerang & 28 & 2,63 \\
15\% Limbah Botol Plastik + & 14 & 3,92 \\
15\% Limbah Cangkang Kerang & 28 & 2,68 \\
20\% Limbah Botol Plastik + & 14 & 3,06 \\
20\% Limbah Cangkang Kerang & 28 & 2,32 \\
\hline
\end{tabular}

Adapun hasil dari pengujian kuat tekan Paving block dengan substitusi limbah botol plastik dan limbah botol kaca dapat dilihat pada Tabel 3 dan Gambar 3.

Berdasarkan hasil pengujian kuat tekan Paving block menunjukkan hasil bahwa limbah botol plastik dan limbah botol kaca mampu meningkatkan niai kuat tekan Paving block dan nilai kuat tekan optimum di umur 28 hari adalah pada variasi $10 \%$ limbah botol plastik $+10 \%$ limbah botol kaca dengan nilai kuat tekan sebesar 8,8 MPa dan termasuk kedalam mutu D yang dapat digunakan untuk taman dan penggunaan lain.

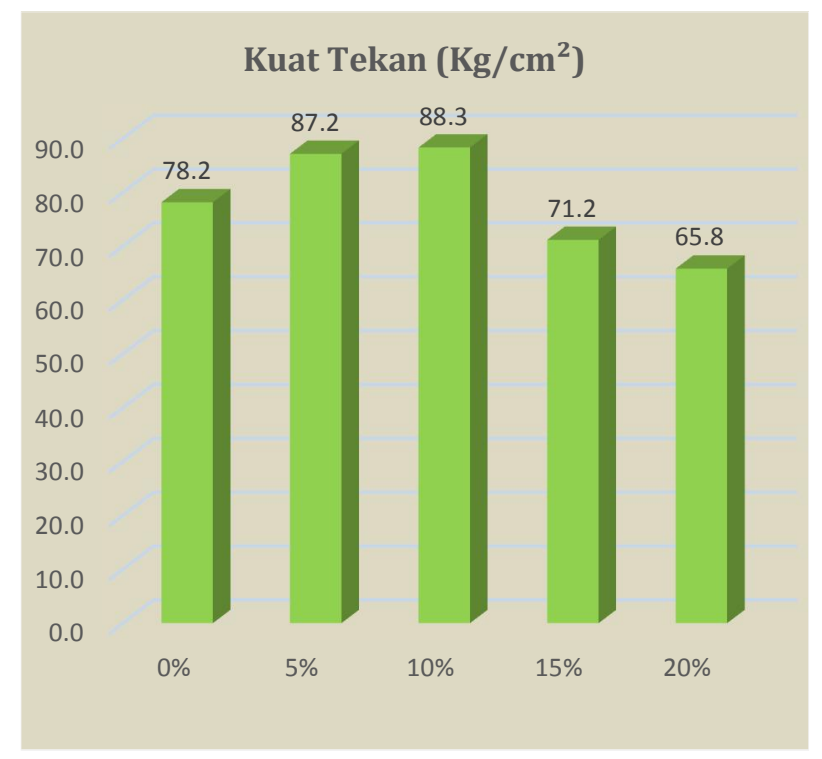

Gambar 3. Hasil Pengujian Kuat Tekan Paving block Umur 28 Hari

Tabel 3. Hasil Uji Kuat Tekan Paving block

\begin{tabular}{ccccc}
\hline Variasi & Hari & $\begin{array}{c}\text { Luas Permukaan } \\
\left(\mathbf{( m m}^{2}\right)\end{array}$ & $\begin{array}{c}\text { Kuat Tekan } \\
\text { Rata-rata } \\
\left(\mathbf{K g} / \mathbf{c m}^{2}\right)\end{array}$ & $\begin{array}{c}\text { Kuat Tekan } \\
\text { Rata-rata } \\
(\mathbf{M P a})\end{array}$ \\
\hline 0\% Limbah Botol Plastik + & 7 & 200 & 62,25 & 6,2 \\
0\% Limbah Botol Kaca & 14 & 200 & 73,3 & 7,3 \\
& 28 & 200 & 78,2 & 7,8 \\
5\% Limbah Botol Plastik + & 7 & 200 & 70,0 & 7 \\
5\% Limbah Botol Kaca & 14 & 200 & 75,8 & 7,6
\end{tabular}




\begin{tabular}{ccccc} 
& 28 & 200 & 87,2 & 8,7 \\
10\% Limbah Botol Plastik + & 7 & 200 & 65,8 & 6,6 \\
10\% Limbah Botol Kaca & 14 & 200 & 70,0 & 7 \\
& 28 & 200 & 88,3 & 8,8 \\
15\% Limbah Botol Plastik + & 7 & 200 & 51,7 & 5,2 \\
15\% Limbah Botol Kaca & 14 & 200 & 58,3 & 5,8 \\
& 28 & 200 & 71,2 & 7,1 \\
20\% Limbah Botol Plastik + & 7 & 200 & 42,5 & 4,3 \\
20\% Limbah Botol Kaca & 14 & 200 & 50,0 & 5 \\
& 28 & 200 & 65,8 & 6,6 \\
\hline
\end{tabular}

Tabel 4. Hasil Uji Penyerapan Air Paving block

\begin{tabular}{ccc}
\hline Variasi & Hari & Rata-rata Penyerapan (\%) \\
\hline 0\% Limbah Botol Plastik + & 14 & 4,19 \\
0\% Limbah Botol Kaca & 28 & 2,63 \\
5\% Limbah Botol Plastik + & 14 & 4,06 \\
5\% Limbah Botol Kaca & 28 & 2,50 \\
10\% Limbah Botol Plastik + & 14 & 3,96 \\
10\% Limbah Botol Kaca & 28 & 2,24 \\
15\% Limbah Botol Plastik + & 14 & 3,60 \\
15\% Limbah Botol Kaca & 28 & 2,08 \\
20\% Limbah Botol Plastik + & 14 & 3,02 \\
20\% Limbah Botol Kaca & 28 & 1,81 \\
\hline
\end{tabular}

Dari tabel nilai nilai persentase penyerapan air Paving block pada variasi campuran optimum dari hasil nilai kuat tekan optimum pada variasi $10 \%$ limbah botol plastik + $10 \%$ limbah botol kaca didapatkan nulai persentase penyerapan sebesar 2,24\%.

Berdasarkan pengujian yang telah dilakukan menunjukkan bahwa Paving block ramah lingkungan berbasis limbah botol plastik kemasan air mineral dengan limbah cangkang kerang dan limbah botol kaca sebagai bahan substitusi terhadap semen dapat meningkatkan nilai kuat tekan Paving block. Nilai kuat tekan tersebut lebih tinggi dibandingkan nilai kuat tekan Paving block normal yang bernilai 7,8 Mpa. Hal ini dapat dilihat dari kenaikan nilai kuat tekan terhadap Paving block normal sebesar 23,96\% untuk variasi Paving block substitusi 10\% limbah botol plastik $+10 \%$ limbah cangkang kerang sedangkan untuk variasi Paving block substitusi 10\% limbah botol plastik $+10 \%$ botol kaca terjadi kenaikan sebesar 6,07 \% terhadap Paving block normal. Selain itu juga, penggunan limbah botol plastik kemasan air mineral dengan limbah cangkang kerang dan limbah botol kaca yang semakin banyak dapat memperkecil nilai penyerapan air.

Hasil perbandingan variasi optimum Paving block berbasis limbah botol plastik kemasan air mineral dengan limbah cangkang kerang dan limbah botol kaca sebagai bahan substitusi semen bahwa variasi Paving block substitusi 10\% limbah botol plastik $+10 \%$ limbah cangkang kerang memiliki hasil terbaik dengan nilai kuat tekan sebesar $12,8 \mathrm{MPa}$ serta nilai persentase penyerapan didapatkan sebesar $2,63 \%$ dan dikategorikan ke dalam mutu $\mathrm{C}$ yang dapat digunakan untuk pejalan kaki. 


\section{KESIMPULAN}

Penggunaan bahan substitusi 10\% limbah botol plastik $+10 \%$ limbah cangkang kerang dapat menaikkan nilai kuat tekan pada umur 28 hari yaitu sebesar $12,8 \mathrm{MPa}$ yang termasuk kedalam mutu C, persyaratan tersebut sesuai dalam SNI 03-0691-1996 yang mana nilai kuat tekan pada mutu $\mathrm{C}$ yang digunakan untuk pejalan kaki. Sedangkan penggunaan bahan substitusi 10\% limbah botol plastik $+10 \%$ limbah botol kaca dengan nilai kuat tekan sebesar 8,8 MPa termasuk kedalam mutu D yang dapat digunakan untuk taman dan penggunaan lain. Penambahan limbah botol plastik kemasan air mineral dengan limbah cangkang kerang dan limbah botol kaca yang semakin banyak dapat memperkecil nilai penyerapan air. Hal ini ditunjukkan dengan semakin besar persentase bahan substitusi yag digunakan maka semakin kecil persentase penyerapan air dari Paving block. Berdasarkan dari hasil penelitian maka pemanfaatan limbah botol plastik kemasan air mineral dan limbah cangkang kerang sebagai substitusi pasir dan semen pada campuran Paving block memberikan hasil yang baik dibandingkan dengan Paving block substusi limbah botol plastik kemasan air mineral dan limbah botol kaca, dimana nilai kuat tekan yang didapatkan memiliki mutu yang lebih tinggi. Namun demikian kedua variasi Paving block tersebut dapat dijadikan sebagai alternatif bahan konstruksi ramah lingkungan.

\section{DAFTAR PUSTAKA}

[1] Arif Frasman Sibuea (2013), Pemanfaatan Limbah Botol Plastik Sebagai Bahan Eco Plafie (Economic Plastic Fiber) Pada Paving block Yang Berkonsep Ramah Lingkungan Dengan Uji Tekan, Uji Kejut Serta Serapan Air, Jurnal Teknik Sipil $\begin{array}{lllll}\text { USU. } & \text { Volume } & 2 & \text { No.2. } & \text { ISSN: }\end{array}$ https://jurnal.usu.ac.id/index.php/jts/article/view/2877

[2] Dian Rifany .K, M. Rizal (2011), Pemanfaatan Hasil Pengelolaan Sampah Sebagai Alternatif Bahan Bangunan Konstruksi, Jurnal SMARTek Volume 9 No.1. ISSN : 1693-0460.

http://jurnal.untad.ac.id/jurnal/index.php/SMARTEK/article/view/619/0

[3] R. Agus Murdiyoto (2011), Pemanfaatan Limbah Botol Plastik Jenis Pet (Poly Ethylene Terephthalate) Untuk Agregat Kasar Pembuatan Paving block, Jakarta, Tesis Universitas Indonesia.

http://lib.ui.ac.id/file?file=digital/20291144-T29610-Pemanfaatan\%20limbah.pdf

[4] Erwin Wijaya Kusuma (2012), Pemanfaatan Limbah Kulit Kerang Sebagai Bahan Campuran Pembuatan Paving block, Universitas Pembangunan Nasional Veteran. JawaTimur. http://eprints.upnjatim.ac.id/4383/

[5] Rida Madya T. F. R., Essy A., Elly T. (2012), Studi Sifat Mekanik Paving block Terbuat Dari Limbah Adukan Beton Dan Serbuk Kaca, Universitas Indonesia. Jakarta.

http://www.lib.ui.ac.id/naskahringkas/2015-08/SRida\%20Madya\%20Tresna\%20Febria\%20Resniyanto

[6] ---------, SNI 03-0691-1996, Bata Beton (Paving block), BSN. 